\title{
The effects of preoperative oral pregabalin and perioperative intravenous lidocaine infusion on postoperative morphine requirement in patients undergoing laparatomy
}

\author{
Senniye Ulgen Zengin MD, Ayten Saracoglu MD, Zeynep Eti MD, Tumay Umuroglu MD, Fevzi Yilmaz Gogus MD
}

\begin{abstract}
SU Zengin, A Saracoglu, Z Eti, T Umuroglu, FY Gogus. The effects of preoperative oral pregabalin and perioperative intravenous lidocaine infusion on postoperative morphine requirement in patients undergoing laparatomy. Pain Res Manag 2015;20(4):179-182.
\end{abstract}

OBJECTIVES: To evaluate and compare the effects of preoperative oral pregabalin and perioperative intravenous lidocaine infusion on postoperative morphine requirement, adverse effects, patients' satisfaction, mobilization, time to first defecation and time to discharge in patients undergoing laparotomy.

METHODS: Eighty patients (18 to 65 years of age) undergoing elective laparotomy were randomly divided into four groups ( $n=20$ in each group): group C, placebo capsules and normal saline infusion perioperatively (control); group L, placebo capsules and lidocaine $1 \mathrm{mg} / \mathrm{kg}$ intravenous bolus dose followed by $2 \mathrm{mg} / \mathrm{kg} / \mathrm{h}$ infusion until skin closure; group P, $150 \mathrm{mg}$ oral pregabalin and normal saline infusion perioperatively; and group PL, $150 \mathrm{mg}$ oral pregabalin and lidocaine $2 \mathrm{mg} / \mathrm{kg} / \mathrm{h}$ infusion until skin closure. Hemodynamic parameters, visual analogue scale (VAS) scores, analgesic consumption, side effects, time to mobilization, time to first defecation, time to discharge and patients' satisfaction were recorded.

RESULTS: VAS scores of group L, group P and group PL were lower than group $\mathrm{C}(\mathrm{P}<0.05)$. Morphine consumption of group $\mathrm{P}$ and group $\mathrm{PL}$ was lower than group $\mathrm{C}(\mathrm{P}<0.05)$. Incidence of nausea in group $\mathrm{C}$ was higher than group $\mathrm{L}$ and group PL. Time to first defecation and mobilization were shorter in group L and group PL compared with group $\mathrm{C}(\mathrm{P}<0.05)$. CONCLUSION: Preoperative oral pregabalin and perioperative intravenous lidocaine infusion decreased postoperative VAS scores. Preoperative oral pregabalin decreased morphine requirement and perioperative intravenous lidocaine infusion hastened gastrointestinal motility and mobilization, and decreased the incidence of nausea in patients undergoing laparotomy. Therefore, preoperative pregabalin with or without lidocaine provides superior pain relief in patients undergoing laparatomy.

Key Words: Laparatomy; Lidocaine; Postoperative pain; Pregabalin

\section{Les effets de la prégabaline préopératoire par voie orale et de la perfusion intraveineuse de lidocaïne périopératoire sur les besoins postopératoires en morphine des patients qui subissent une laparotomie}

OBJECTIFS : Évaluer et comparer les effets de la prégabaline préopératoire par voie orale et de la perfusion intraveineuse périopératoire de lidocaïne sur les besoins postopératoires en morphine, les réactions indésirables, la satisfaction des patients, la mobilisation, le délai jusqu'à la première défécation et le délai jusqu'au congé chez les patients qui subissent une laparotomie.

MÉTHODOLOGIE : Quatre-vingts patients (de 18 à 65 ans) qui subissaient une laparotomie non urgente ont été répartis au hasard en quatre groupes $(\mathrm{n}=20$ dans chaque groupe). Le groupe $\mathrm{C}$ recevait des capsules placebo et une perfusion de soluté physiologique (sujets témoins); le groupe L, des capsules placebo et un bolus intraveineux de $1 \mathrm{mg} / \mathrm{kg}$ de lidocaïne suivi d'une perfusion de $2 \mathrm{mg} / \mathrm{kg} / \mathrm{h}$ jusqu'à la guérison de la plaie; le groupe $\mathrm{P}, 150 \mathrm{mg}$ de prégabaline par voie orale et une perfusion périopératoire de soluté physiologique; et le groupe PL, $150 \mathrm{mg}$ de prégabaline par voie orale et une perfusion de $2 \mathrm{mg} / \mathrm{kg} / \mathrm{h}$ de lidocaïne jusqu'à la guérison de la plaie. Les chercheurs ont consigné les paramètres hémodynamiques, les scores de l'échelle analogique visuelle (ÉAV), la consommation d'analgésiques, les réactions indésirables, le délai jusqu'à la mobilisation, le délai jusqu'à la première défécation, le délai jusqu'au congé et la satisfaction des patients.

RÉSULTATS : Les scores de l'ÉAV des groupes L, P et PL étaient plus faibles que ceux du groupe $\mathrm{C}(\mathrm{P}<0,05)$. La consommation de morphine par les groupes $\mathrm{P}$ et $\mathrm{PL}$ était plus faible que celle du groupe $\mathrm{C}(\mathrm{P}<0,05)$. L'incidence de nausées dans le groupe $\mathrm{C}$ était plus élevée que dans les groupes L et PL. Le délai jusqu'à la première défécation et la mobilisation étaient plus courts dans les groupes $\mathrm{L}$ et $\mathrm{PL}$ que dans le groupe $\mathrm{C}(\mathrm{P}<0,05)$. CONCLUSION : La prégabaline préopératoire par voie orale et la perfusion intraveineuse périopératoire de lidocaïne réduisaient les scores postopératoires de l'ÉAV. La prégabaline préopératoire par voie orale réduisait les besoins en morphine, tandis que la perfusion intraveineuse périopératoire de lidocaïne accélérait la motilité gastro-intestinale et la mobilisation et réduisait l'incidence de nausées chez les patients qui subissaient une laparotomie. Ainsi, la prégabaline préopératoire avec ou sans lidocaïne assure un soulagement supérieur de la douleur chez les patients qui subissent une laparotomie.

dose of opioids by combining drugs and methods with different modes of action (5).

Pain after surgery has a neuropathic component as well as somatic and visceral characteristics, and agents that are effective in the treatment of neuropathic pain are effective in reducing central sensitization (6). Pregabalin is a gamma-aminobutyric acid analogue with anticonvulsant effect. Although the primary indication is neuropathic pain, recent studies have evaluated the efficacy of pregabalin in the treatment of acute postoperative pain $(7,8)$. management of postoperative pain in patients undergoing major to experience moderate to severe pain (1-3). Although regional analgesia techniques provide intense pain relief, they may result in rare but potentially devastating complications (4). Opioid-related side effects may delay recovery and rehabilitation. Recent studies have focused on the concept of 'multimodal analgesia' to achieve optimal analgesia, and to reduce the side effects and the required
Department of Anesthesiology, Marmara University School of Medicine, Istanbul, Turkey

Correspondence: Dr Ayten Saracoglu, Department of Anesthesiology, Bilim University School of Medicine, Florence Nightingale Hospital Abide-i

Hurriyet Cad. No:164, Sisli Istanbul, Turkey. Telephone 90-2122244954, fax 90-2122244982, e-mail anesthesiayten@gmail.com
OPEN $\bigcirc$ ACCESS

This open-access article is distributed under the terms of the Creative Commons Attribution Non-Commercial License (CC BY-NC) (http:// creativecommons.org/licenses/by-nc/4.0/), which permits reuse, distribution and reproduction of the article, provided that the original work is properly cited and the reuse is restricted to noncommercial purposes. For commercial reuse, contact support@pulsus.com 
TABLE 1

Patient characteristics and duration of surgery

\begin{tabular}{lcccc}
\hline & & \multicolumn{3}{c}{ Groups } \\
\cline { 2 - 5 } Characteristic & Control & Pregabalin & Lidocaine & Pregabalin + lidocaine \\
\hline Age, years & $53.2 \pm 15.7$ & $54.0 \pm 23.8$ & $51.1 \pm 26.2$ & $51.7 \pm 19.1$ \\
Body weight, $\mathrm{kg}$ & $70.0 \pm 16.7$ & $69.7 \pm 28.7$ & $72.2 \pm 25.5$ & $74 \pm 25.2$ \\
Sex, male/female, $\mathrm{n} / \mathrm{n}$ & $10 / 10$ & $8 / 12$ & $11 / 9$ & $8 / 12$ \\
Duration of surgery, min & $101.0 \pm 78.0$ & $113.3 \pm 93.6$ & $114.1 \pm 89.8$ & $99.6 \pm 145.6$ \\
\hline
\end{tabular}

Data presented as mean $\pm S D$ unless otherwise specified. $P>0.05$ among groups

TABLE 2

Perioperative mean arterial pressure $(\mathrm{mm} \mathrm{Hg})$ and heart rate (beats $/ \mathrm{min})$

\begin{tabular}{|c|c|c|c|c|c|c|c|c|}
\hline \multirow[b]{2}{*}{ Time } & \multicolumn{2}{|c|}{ Control } & \multicolumn{2}{|c|}{ Pregabalin } & \multicolumn{2}{|c|}{ Lidocaine } & \multicolumn{2}{|c|}{ Pregabalin + lidocaine } \\
\hline & Blood pressure & Heart rate & Blood pressure & Heart rate & Blood pressure & Heart rate & Blood pressure & Heart rate \\
\hline $0 \min$ & $104.3 \pm 40.5$ & $92.2 \pm 36.2$ & $104.6 \pm 31.6$ & $86.3 \pm 28.0$ & $104.5 \pm 28.4$ & $91.2 \pm 27.0$ & $96.2 \pm 35.1$ & $87.4 \pm 33.3$ \\
\hline $15 \min$ & $103.3 \pm 41.3$ & $92.4 \pm 27.2$ & $96.0 \pm 52.5$ & $84.9 \pm 30.6^{*}$ & $91.9 \pm 28.8$ & $86.1 \pm 27.4^{*}$ & $90.8 \pm 42.3$ & $81.5 \pm 29.9^{*}$ \\
\hline $30 \mathrm{~min}$ & $96.5 \pm 47.8$ & $92.3 \pm 24.2$ & $89.7 \pm 35.9$ & $85.4 \pm 27.9^{*}$ & $87.2 \pm 35.0$ & $85.7 \pm 29.8^{*}$ & $92.0 \pm 37.4$ & $84.1 \pm 29.4^{*}$ \\
\hline $60 \mathrm{~min}$ & $94.6 \pm 31.3$ & $89.6 \pm 25.8$ & $89.1 \pm 48.1$ & $82.1 \pm 26.3$ & $91.8 \pm 36.2$ & $74 \pm 21.6$ & $86.1 \pm 30.4$ & $78.8 \pm 24.9$ \\
\hline $90 \mathrm{~min}$ & $87.6 \pm 40.2$ & $83.4 \pm 15.8$ & $87.5 \pm 39.4$ & $80.4 \pm 34.9$ & $91.1 \pm 31.5$ & $74.1 \pm 9.2$ & $84.7 \pm 22.0$ & $75.7 \pm 27.1$ \\
\hline $120 \mathrm{~min}$ & $85.6 \pm 25.4$ & $78.4 \pm 25.6$ & $81.7 \pm 32.7$ & $74.2 \pm 22.7$ & $96.7 \pm 33.1^{*}$ & $73.8 \pm 29.2$ & $73.2 \pm 73.2^{*}$ & $71.5 \pm 31.7$ \\
\hline $150 \mathrm{~min}$ & $75.2 \pm 23.4$ & $72.4 \pm 14.2$ & $84.2 \pm 36.3$ & $74 \pm 12.3$ & $88.0 \pm 24.8$ & $73.7 \pm 31.4$ & $77.5 \pm 18.9$ & $74 \pm 45.1$ \\
\hline
\end{tabular}

Data presented as mean $\pm S D$. ${ }^{*} P<0.05$ versus control

Lidocaine is a local anesthetic agent that produces an analgesic effect by modifying response to neurons in the dorsal horn, and an anti-inflammatory effect by inhibiting migration and metabolic activation of leukocytes (8). Lidocaine has a positive effect on the return of gastrointestinal motility, which has been attributed to earlier mobilization (9-11).

The aim of our study was to investigate the effects of preoperative oral pregabalin and perioperative intravenous lidocaine infusion in patients undergoing laparotomy on postoperative morphine consumption, adverse effects, gastrointestinal motility, patient satisfaction, time to mobilization and time to discharge.

\section{METHODS}

After the approval of the Central Ethics Committee of Pharmaceutical General Directorate of the Ministry of Health (No: 1713 / Date: September 30, 2010) and patients' written consent, the present prospective, randomized, placebo-controlled and double-blinded study included a total of 80 patients, American Society of Anesthesiology classification I to II, 18 to 65 years of age and undergoing elective laparotomy between November 2010 and April 2011. Patients for whom informed consent was not obtained, had American Society of Anesthesiology scores $\geq$ III, liver or kidney failure, chronic pain, epilepsy or other neurological disease or a history of allergy to one of the study drugs were excluded from the study.

The patients were randomly divided into four groups $(n=20$ per group). In group C (control-placebo), patients ingested placebo capsules $12 \mathrm{~h}$ before the operation and on the morning of the operation, and received saline infusion perioperatively. Group L (lidocaine) patients ingested placebo capsules $12 \mathrm{~h}$ before surgery and on the morning of surgery, and received a bolus injection of $1.0 \mathrm{mg} / \mathrm{kg}$ lidocaine at induction of anesthesia, then a continuous infusion with a Braun Perfusor infusion pump (B. Braun Melsungen, Germany) at a rate of $2 \mathrm{mg} / \mathrm{kg} / \mathrm{h}$ during the operation until skin closure. Group P (pregabalin) patients ingested $150 \mathrm{mg}$ pregabalin $12 \mathrm{~h}$ before surgery and on the morning of surgery, and received saline infusion perioperatively. Group PL (pregabalin + lidocaine) patients ingested $150 \mathrm{mg}$ pregabalin $12 \mathrm{~h}$ before surgery and on the morning of surgery, and received bolus injection of $1.0 \mathrm{mg} / \mathrm{kg}$ lidocaine at induction of anesthesia, then a continuous infusion at a rate of $2 \mathrm{mg} / \mathrm{kg} / \mathrm{h}$ perioperatively until skin closure. Randomization was performed with sealed envelope method before the day of surgery when patients arrived to the ward reception area.

Anesthesia was induced with $5 \mathrm{mg} / \mathrm{kg}$ to $7 \mathrm{mg} / \mathrm{kg}$ thiopental sodium and $0.1 \mathrm{mg} / \mathrm{kg}$ intravenous vecuronium bromide in all patients and was maintained with 1 MAC desflurane and 70\% nitrogen dioxide in oxygen. Perioperative heart rate, arterial blood pressure, peripheral oxygen saturation and end-tidal carbon dioxide pressure monitoring were performed and the data were recorded at 30 min intervals. Postoperatively, intravenous morphine was administered until visual analogue scale (VAS) scores were $<30$, and intravenous patient-controlled analgesia (PCA) consisting of $1 \mathrm{mg} / \mathrm{mL}$ morphine solution with $1.5 \mathrm{mg}$ bolus dose and 8 min lockout interval was started in the recovery room.

Postoperative VAS scores (at rest, with coughing and with movement) were first measured in the postanesthesia care unit (time point 0 ). The measurements were recorded at $2 \mathrm{~h}$ intervals for the first $8 \mathrm{~h}, 4 \mathrm{~h}$ intervals for the second $8 \mathrm{~h}$ and continued at $6 \mathrm{~h}$ intervals for $48 \mathrm{~h}$. Measurements included mean arterial pressure, heart rate, respiratory rate, PCA consumption, additional analgesic requirement, side effects, time to mobilization, time to first defecation and time to discharge. Patient satisfaction scores using a four-point Likert scale questionnaire $(0=$ poor, 3 = excellent $)$ were recorded in all patients.

Intraoperatively, measurement of mean arterial pressure and heart rate began following placement of hemodynamic monitors and were measured at $15 \mathrm{~min}$ intevals.

\section{Statistical analysis}

To demonstrate a $30 \%$ difference in postoperative morphine requirement, it was estimated that 19 patients per group would be required for $\alpha=0.05, \beta=0.1$ (power 90\%) with a standard effect size of 1.18 . The data obtained were compared statistically using repeated-measures ANOVA and the post hoc Tukey-Kramer test; nonparametric data were evaluated using the Kruskal-Wallis test. $\mathrm{P}<0.05$ was considered to be statistically significant.

\section{RESULTS}

There was no significant difference among groups in terms of the demographic characteristics and the duration of surgery $(P>0.05$, Table 1). No statistical difference was found among the groups with respect to perioperative mean arterial pressure $(P>0.05$, Table 2). Perioperative heart rate at $15 \mathrm{~min}, 30 \mathrm{~min}$ and $60 \mathrm{~min}$ was significantly lower in group $\mathrm{P}$, group L and group PL compared with group C $(\mathrm{P}<0.05$, Table 2$)$.

No difference was detected among the groups with regard to morphine loading dose in the recovery room $(\mathrm{P}>0.05)$. VAS scores were found to be statistically lower in group $\mathrm{P}$, group $\mathrm{L}$ and group $\mathrm{PL}$ than in group $\mathrm{C}$ between $2 \mathrm{~h}$ and $16 \mathrm{~h}$ postoperatively $(\mathrm{P}<0.05$, Table 3$)$. 
TABLE 3

Postoperative pain rating using visual analogue scale scores (0 $\mathrm{mm}$ to $100 \mathrm{~mm}$ )

\begin{tabular}{lcccc}
\hline Time & Control & Pregabalin & Lidocaine & $\begin{array}{c}\text { Pregabalin }+ \\
\text { lidocaine }\end{array}$ \\
\hline $0 \mathrm{~h}$ & $67.0 \pm 8.8$ & $60.9 \pm 10.5$ & $59.8 \pm 10.0$ & $59.1 \pm 9.7$ \\
$2 \mathrm{~h}$ & $44.2 \pm 7.6$ & $35.9 \pm 9.7^{*}$ & $42.5 \pm 9.6^{*}$ & $38.8 \pm 9.1^{*}$ \\
$4 \mathrm{~h}$ & $42.3 \pm 8.9$ & $31.9 \pm 8.8^{*}$ & $34.2 \pm 10.0^{*}$ & $33.0 \pm 7.8^{*}$ \\
$6 \mathrm{~h}$ & $39.8 \pm 6.5$ & $27.9 \pm 5.2^{*}$ & $33.3 \pm 8.4^{*}$ & $28.8 \pm 5.8^{*}$ \\
$8 \mathrm{~h}$ & $34.0 \pm 7.2$ & $24.0 \pm 5.3^{*}$ & $31.0 \pm 8.9^{*}$ & $29.1 \pm 5.2^{*}$ \\
$12 \mathrm{~h}$ & $32.3 \pm 6.6$ & $23.4 \pm 5.7^{*}$ & $29.3 \pm 5.2$ & $28.8 \pm 6.3^{*}$ \\
$16 \mathrm{~h}$ & $29.0 \pm 7.0$ & $24.0 \pm 5.7^{*}$ & $28.2 \pm 6.7$ & $26.3 \pm 4.2^{*}$ \\
$22 \mathrm{~h}$ & $25.0 \pm 7.4$ & $23.7 \pm 4.9$ & $24.7 \pm 4.8$ & $25.3 \pm 4.5$ \\
$28 \mathrm{~h}$ & $27.2 \pm 5.8$ & $24.3 \pm 5.7$ & $27.1 \pm 9.4$ & $23.4 \pm 6.5$ \\
$34 \mathrm{~h}$ & $25.4 \pm 4.1$ & $25.5 \pm 7.0$ & $23.9 \pm 3.3$ & $22.7 \pm 4.6$ \\
$40 \mathrm{~h}$ & $24.8 \pm 5.8$ & $24.2 \pm 3.0$ & $22.6 \pm 2.9$ & $22.9 \pm 5.0$ \\
$48 \mathrm{~h}$ & $23.1 \pm 4.2$ & $22.05 \pm 2.9$ & $21.25 \pm 4.1$ & $19.5 \pm 5.1$ \\
\hline
\end{tabular}

Data presented as mean $\pm S D$. ${ }^{*} P<0.05$ versus control

Total PCA morphine consumption was lower in the first postoperative $4 \mathrm{~h}$ interval in group $\mathrm{P}$ (mean $[ \pm \mathrm{SD}] 16.9 \pm 13.1 \mathrm{mg}$ ) and group PL (16.4 $\pm 17.5 \mathrm{mg})$ compared with the control group $(24.2 \pm 16.4 \mathrm{mg})$ $(\mathrm{P}<0.05)$. Morphine consumption was also significantly lower after the postoperative $34 \mathrm{~h}$ interval in group $\mathrm{P}(53.5 \pm 49.1 \mathrm{mg})$ and group PL $(65.9 \pm 72.8 \mathrm{mg})$ compared with the control group $(87.1 \pm 49.3 \mathrm{mg})$ $(\mathrm{P}<0.05)$. Compared with group $\mathrm{C}$, morphine consumption was statistically lower in group P only at the $40 \mathrm{~h}(58.6 \pm 53.6 \mathrm{mg}$ versus $93.2 \pm 52.9 \mathrm{mg})$ and $48 \mathrm{~h}(62.8 \pm 55.4 \mathrm{mg}$ versus $99.7 \pm 54.7 \mathrm{mg})$ intervals $(\mathrm{P}<0.05)$.

There was no difference among groups with respect to return of bowel sounds. Time to first defecation and mobilization times were statistically shorter in group L and group PL compared with group C $(\mathrm{P}<0.05$, Table 4).

There was no significant difference among groups in terms of itching. The incidence of nausea was lower in group $\mathrm{L}$ and group PL (two of 18 and five of 15 patients experienced nausea, respectively, $\mathrm{P}<0.05$ ). Seven patients in group $\mathrm{P}$ and 13 patients in group $\mathrm{C}$ had nausea (Table 5).

There was no significant difference among groups in terms of patient satisfaction.

\section{DISCUSSION}

In the present study, it was found that preoperative oral pregabalin reduced postoperative VAS scores and morphine requirements, while perioperative intravenous lidocaine infusion had a positive effect on VAS scores, gastrointestinal functions, mobilization time and decreased the incidence of nausea. Pregabalin with or without lidocaine provided superior pain relief in patients undergoing laparatomy.

Postoperative pain may have adverse effects on the respiratory, cardiovascular, endocrine, immune, gastrointestinal and locomotor systems, particularly after major surgical procedures, as well as disrupting patient comfort, increasing morbidity and even mortality (1). Postoperative pain has a neuropathic component, which may be perceived as hyperalgesia, hyperesthesia or hypoesthesia as a result of peripheral and central sensitization. The incidence of acute postoperative neuropathic pain has been reported to be $1 \%$ to $3 \%$ in 2002 (12).

Administration of systemic opioid and nonsteroidal anti-inflammatory drugs, or injection of neuraxial or perineural local anesthetic and opioid combinations are the most frequently used methods for postoperative pain treatment. However, these methods are inadequate for many patients. Therefore, anticonvulsant agents such as gabapentin and pregabalin, which are effective in the treatment of chronic neuropathic pain, have been used in the treatment of acute postoperative pain in recent years $(2,13,14)$.

Doses of gabapentin and pregabalin for treatment of postoperative pain ranged from $300 \mathrm{mg}$ to $1200 \mathrm{mg}$ and $150 \mathrm{mg}$ to $300 \mathrm{mg}$, respectively $(14,15)$. Pregabalin was chosen for the present study because it is
TABLE 4

Time to first bowel sound, defecation, mobilization and discharge, $\mathrm{h}$

\begin{tabular}{lcccc}
\hline Variable & Control & Pregabalin & Lidocaine & $\begin{array}{c}\text { Pregabalin + } \\
\text { lidocaine }\end{array}$ \\
\hline Bowel sound & $22.9 \pm 6.1$ & $22.0 \pm 3.5$ & $24.8 \pm 3.5$ & $24.4 \pm 3.6$ \\
Defecation & $40.8 \pm 10.0$ & $38.6 \pm 6.1$ & $32.9 \pm 5.5^{*}$ & $34.5 \pm 5.3^{*}$ \\
Mobilization & $19.2 \pm 3.0$ & $18.3 \pm 2.8$ & $17.3 \pm 2.4^{*}$ & $17.1 \pm 2.8^{*}$ \\
Discharge & $104.4 \pm 27.0$ & $98.5 \pm 10.6$ & $97.7 \pm 12.5$ & $92.3 \pm 9.7$ \\
\hline \multicolumn{2}{l}{ Data presented as mean $\pm S D .{ }^{*} P<0.05$ versus control }
\end{tabular}

TABLE 5

Postoperative side effects

\begin{tabular}{lcccc}
\hline Side effect & Control & Pregabalin & Lidocaine & $\begin{array}{c}\text { Pregabalin + } \\
\text { lidocaine }\end{array}$ \\
\hline Pruritus (yes/no) & $4 / 16$ & $0 / 20$ & $1 / 19$ & $1 / 19$ \\
Nausea (yes/no) & $13 / 7$ & $7 / 13$ & $2 / 18^{*}$ & $5 / 15^{*}$ \\
\hline
\end{tabular}

${ }^{*} P<0.05$ between groups

easier to use in acute pain due to its linear pharmacokinetics (16). As in our study, it has been observed that gabapentin and pregabalin decreased postoperative opiate requirements $(17,18)$.

In patients undergoing laparoscopic gastrectomy, a single preoperative dose of $150 \mathrm{mg}$ pregabalin decreased VAS values and morphine consumption during the first $24 \mathrm{~h}$ postoperatively (19). Paech et al (20) administered a preoperative dose of pregabalin $100 \mathrm{mg}$ and intraoperative acetaminophen in patients undergoing minor gynecological surgery and reported that postoperative pain scores and the fentanyl consumption were similar to the placebo group. This study was performed in ambulatory patients, and side effects and analgesic requirements were interrogated later by telephone. Early discharge also reduced the use of parenteral analgesics.

Systemic local anesthetics have been used for acute and chronic pain for many years. The preferred intravenous anesthetic is lidocaine because of rapid onset and intermediate duration of action (21). Although there are a number of studies concerning the effects of pregabalin and lidocaine on postoperative pain, mobilization, time to discharge and postoperative gastrointestinal system functions, ours is the first study comparing the effects of the combination of two medications with each alone and with placebo. We used two $150 \mathrm{mg}$ doses of pregabalin ( $12 \mathrm{~h}$ and $45 \mathrm{~min}$ before surgery). In most studies, pregabalin was administered $1 \mathrm{~h}$ to $2 \mathrm{~h}$ before surgery as a single dose $(22,23)$. In a study investigating the effects of perioperative infusion of lidocaine on major abdominal surgery (20), patients were administered a $1.5 \mathrm{mg} / \mathrm{kg}$ loading dose $30 \mathrm{~min}$ before surgical incision followed by $1.5 \mathrm{mg} / \mathrm{kg} / \mathrm{h}$ infusion until the end of the first postoperative hour; the total dose of morphine administered by PCA and the additional morphine requirements were found to be lower than those of control group.

The effect of systemic lidocaine on discharge of patients undergoing colorectal surgery was examined and it was reported that bowel function started earlier with lidocaine and that patients were discharged earlier (11). Groudine et al (24) found similar results in patients undergoing radical retropubic prostatectomy. In the two studies, infusion of lidocaine continued until the end of the first postoperative hour. We stopped lidocaine infusion after closure of skin incision and found the mean time to defecation was shorter. In the two studies related to the postoperative lidocaine infusion, no analgesic effect could be observed $(11,25)$. It was believed that lidocaine infusion, to be effective, should be given during nociceptive stimulus (26). Lidocaine was also found to be as effective as epidural block on postoperative pain, bowel functions and hospital discharge in patients undergoing colonic resection (27).

The occurrence and the incidence of side effects is important for the quality of postoperative analgesia. Pregabalin has negligible interaction with other drugs and is well tolerated. Adverse effects such as somnolence, dizziness, confusion, headache, ataxia and weight gain 
have been reported (28-31). While many of these side effects are due to chronic use of pregabalin, the most common side effects in postoperative patients are dizziness, somnolence and sedation. We did not detect any statistically significant difference in pruritus. Schulmeyer et al (19) reported a significant reduction in nausea, vomiting and the use of antiemetics in patients undergoing laparoscopic gastrectomy with preoperative $150 \mathrm{mg}$ pregabalin. Preoperative pregabalin $150 \mathrm{mg}$ did not increase the incidence of side effects in patients undergoing laparoscopic cholecystectomy. However, Mathiesen et al (30) administered pregabalin $300 \mathrm{mg}$ and pregabalin $300 \mathrm{mg}$ plus dexamethasone $8 \mathrm{mg}$ to patients undergoing arthroscopy under spinal anesthesia and found that significantly increased sedation and nausea occurred in the pregabalin only group compared with pregabalin plus dexamethasone group and controls. The antiemetic effect of dexamethasone may contribute to this result. More adverse effects such as drowsiness, blurred vision and difficulty in walking were reported in patients given pregabalin $600 \mathrm{mg}$ (31). It has been shown that the higher the dose used, the more analgesic

\section{REFERENCES}

1. Ceyhan D, Güleç MS. Is postoperative pain only a nociceptive pain? [Turkish] Agri 2010;22:47-52.

2. Gilron I. The role of anticonvulsant drugs in postoperative pain management: A bench to bed side perspective. Can J Anesth 2006;53:562-71.

3. Pyati S, Gan TJ. Perioperative pain management. CNS Drugs 2007;21:185-211.

4. Agarwal A, Kishore K. Complications and controversies of regional anaesthesia: A review. Indian J Anaesth 2009;53:543-53.

5. Ziemann-Gimmel P, Hensel P, Koppman J, et al. Multimodal analgesia reduces narcotic requirements and antiemetic rescue medication in laparoscopic Roux-en-Y gastric bypass surgery. Surg Obes Relat Dis 2013;9:975-80.

6. Woolf CJ. Central sensitization: Implicationsor the diagnosis and treatment of pain. Pain 2011;152:2-15.

7. Rogawski MA, Bazil CW. New molecular targets for antiepileptic drugs: Alpha(2)delta, SV2A, and K(v)7/KCNQ/M potassium channels. Curr Neurol Neurosci Rep 2008;8:345-52.

8. Eisenberg E, River Y, Shiffrin A, et al. Antiepileptic drugs in the treatment of neuropathic pain. Drugs 2007;67:1265-89.

9. Hollman M, Durieux EM. Local anesthetics and the inflammatory response: A new therapeutic indication? Anesthesiology 2000;93:858-75.

10. Marret E, Rolin M, Bonnet F. Meta-analysis of intravenous lidocaine and postoperative recovery after abdominal surgery. Br J Surg 2008;95:1331-8.

11. Herroeder S, Pecher S, Schönherr E. Systemic lidocaine shortens length of hospital stay after colorectal surgery. Ann Surg 2007;246:192-200.

12. Schug SA. Is neuropathic pain an acute problem? Acute Pain 2002;4:43-7.

13. Verma V, Singh N, Singh Jaggi A. Pregabalin in neuropathic pain: Evidences and possible mechanisms. Curr Neuropharmacol 2014;12:44-56.

14. Sporn J, Single N, Chelly J. Efficacy and safety of pregabalin in the treatment of postoperative pain following inguinal hernioplasty. Eur J Anesthesiol 2010;27:202-4.

15. Mikkelsen S, Hilsted KL, Andersen PJ. The effect of gabapentin on postoperative pain following tonsillectomy in adults. Acta Anaesthesiol Scand 2006;50:809-15.

16. Schulze-Bonhage A. Pharmacokinetic and pharmacodynamic profile of pregabalin and its role in the treatment of epilepsy. Expert Opin Drug Metab Toxicol 2013;9:105-15.

17. Schmidt PC, Ruchelli G, Mackey SC, et al. Perioperative gabapentinoids: Choice of agent, dose, timing, and effects on chronic postsurgical pain. Anesthesiology. 2013;119:1215-21. effect as well as the higher incidence of adverse effects are observed. To balance the analgesic effect and side effects, we consider that using two doses of $150 \mathrm{mg}$ may be more appropriate. High-dose lidocaine has been reported to have side effects such as paresthesia, nystagmus, convulsion and arrhythmia; however, we did not observe any of these effects.

\section{CONCLUSION}

Preoperative oral pregabalin decreased VAS scores. Intraoperative lidocaine infusion decreased the incidence of nausea and hastened the return of gastrointestinal motility. We conclude that preoperative pregabalin with or without lidocaine reduced morphine requirements and provided superior pain relief compared with placebo in patients undergoing laparatomy.

DISCLOSURES: The authors have no funding or conflicts of interest to disclose.

18. Weinbroum AA. Non-opioid IV adjuvants in the perioperative period: Pharmacological and clinical aspects of ketamine and gabapentinoids. Pharmacol Res 2012;65:411-29.

19. Schulmeyer M. Analgesic effects of a single preoperative dose of pregabalin after laparoscopic sleeve gastrectomy. Obes Surg 2010;20:1678-81

20. Paech M, Goy R, Chua S, et al. A randomized placebo controlled trial of preoperative oral pregabalin for postoperative pain relief after minor gynecological surgery. Anesth Analg 2007;105:1449-53.

21. Moore PA, Hersh EV. Local anesthetics: Pharmacology and toxicity. Dent Clin North Am 2010;54:587-99.

22. Yogasakaran S, Menzes F. Acute neuropathic pain after surgery: Are we treating them early/late? Acute Pain 2005;7:145-9.

23. Jokela R, Ahonen J, Tallgren M, et al. Premedication with pregabalin 75 or $150 \mathrm{mg}$ with ibuprofen to control pain after day-case gynaecological laparoscopic surgery. $\mathrm{Br} \mathrm{J}$ Anaesth 2008; $100: 834-40$

24. Groudine SB, Hugh A, Fisher G. Intravenous lidocaine speeds the return of bowel function, decreases postoperative pain, and shortens hospital stay in patients undergoing radical retropubic prostatectomy. Anesth Analg 1998;86:235-9.

25. Koppert W, Weigand M, Neumann F. Perioperative intravenous lidocaine has preventive effects on postoperative pain and morphine consumption after major abdominal surgery. Anesth Analg 2004;98:1050-5.

26. Wallace MS, Laitin S, Licht D, et al. Concentration-effect relations for intravenous lidocaine infusions in human volunteers: Effects on acute sensory thresholds and capsaicin-evoked hyperpathia. Anesthesiology 1997;86:1262-72.

27. Swenson RB, Gottschalk A, Wells L. Intravenous lidocaine is as effective as epidural bupivacaine in reducing ileus duration, hospital stay, and pain after open colonic resection. Reg Anesth Pain Manag 2010;35:370-6.

28. Arroyo S. Pregabalin add-on treatment: A randomized, double blind, placebo-controlled, dose-response study in patients with partial seizures. Epilepsia 2004;45:20-7.

29. Agarwal A, Guatam S, Gupta D, et al. Evaluation of a single preoperative dose of pregabalin for attenuation of postoperative pain after laparoscopic cholecystectomy. Br J Anaesth 2008;101:700-4.

30. Mathiesen O, Jakobsen S, Holm HE, et al. Pregabalin and dexamethasone for postoperative pain control: A randomized controlled study in hip arthroplasty. Br J Anaesth 2008;101:535-41.

31. Jokela R. A randomized controlled trial of perioperative administration of pregabalin for pain after laparoscopic hysterectomy. Pain 2008;134:106-12. 